the pattern of higher education now being enforced.

This week's retrospective view of what the association has done may in this sense help. The record shows that it was not, even in its heroic days, a strictly academic body but one that sought to build bridges between the scientific community and other groups of interested people. Who would say that the need for that service has diminished in the past 150 years? But what has changed is the nature of society. Many of the dreams of the 1830 s have come true - people are more healthy, more wealthy and even wiser. Questions such as the validity of evolutionary theories, the ethical problems thrown up by modern biology and the economic future of technological societies concern people of all backgrounds, not just scientists. No single body could resolve all those conundrums. But the British Association is well placed to promote the intelligent discussion of them. It is also better qualified for that task than for its present attempts at popularization at which it is not especially skilled. Is it too much to hope that this week's birthday party will give a substantial proportion of the membership the resolve to set off in this new (but also old) direction?

\section{Mr Watt's fight}

One of the colourful characters of the new United States Administration and the most eccentric is Mr James Watt, the Secretary of the Interior. For most of the past six months, $\mathrm{Mr}$ Watt has been in one scrape after another and has succeeded in elevating the Department of the Interior from its traditional obscurity to a position of one of the most controversial of government departments. For $\mathrm{Mr}$ Watt is a zealot, one who appears to believe that the great resources of the United States should be more fully harnessed to the cause of economic growth, even if the consequences are that this or that patch of wilderness or national park will be sacrificed. The outrage of the environmentalists is predictable. But $\mathrm{Mr}$ Watt may now be surprised to find himself in trouble with Congress, not so much for his policies (which nevertheless are not much liked) as for his manner (for his certainty that he is right has offended even some of his potential friends).

Mr Watt's problem is familiar. He is by all accounts a man of high principle (and a deeply religious conviction). He takes the view that mankind has a duty to ensure its own survival, to which end the efficient exploitation of natural resources is essential. High principles are not, of course, unwelcome in politics indeed, some would say that they are all too rare. What Mr Watt appears not to have appreciated or to have had time to learn (for he had no previous experience of practical politics) is that there are many occasions on which equally high-minded people differ radically in their opinions about courses of action that should be followed. Mr Watt's failure is especially tragic, apart from the trouble he is likely to bring down on himself, because much of what he seeks to do is sensible.

The latest row with which $\mathrm{Mr}$ Watt has been caught up concerns a proposal to license drilling for oil and gas in a wilderness area in Montana. The issue is simple. The wilderness area, which spans the Great Divide, is federal land. The statutes which set it aside as wilderness can be amended only by Congress. The chances of finding oil and gas are said to be good, at least on paper, but so far not a single exploratory borehole has been drilled. $\mathrm{Mr}$ Watt appears to favour letting a few licences to drill in this remote area of the United States, thus confirming his critics in their view that he is the kind of man who would allow the Lincoln Memorial to be broken up if there were no marble for some other building project.

Mr Watt is right to worry about the supply of oil and natural gas. That is his job. He would also be on firm ground if he were to argue that circumstances are foreseeable in which shortages of energy are so great that environmental considerations of all kinds would have to be set aside. His mistake, on the most generous reading of his actions since taking office, is that he supposes that his assessment of the urgency of the need takes precedence over that of other people. Although, in the days of President Lyndon Johnson's Great Society, wilderness areas were dedicated and national parks extended without nearly enough thought for the consequences, they were popular accretions; people have grown fond of them. And United States voters will not give them up without a good reason. Browbeating from $\mathrm{Mr}$ Watt is almost certain to be counter-productive.

Much will depend in the weeks ahead on whether Mr Watt seeks to win his case or, less prudently, to make his point that conservation must now take a back seat. In the first and prudent case, he will postpone the issue of whether people should begin immediately to drill for oil and gas in Montana, and will instead try to hammer out a rational policy on conservation. When should the need for natural resources take precedence over the conservation of the native or artificial state of some valued tract of land? What conditions must be attached to such projects to strike a proper balance between economic efficiency and natural beauty, the preservation of habitats and of species? By what means can some kind of economic value be put on a tract of wilderness? And how much land can even the United States afford to put in quarantine for ever? These questions were scandalously glossed over in the past two decades, when any tract of federal land not obviously an eyesore was liable to become a conservation area overnight. But, as things are, and however unfair it may seem, $\mathrm{Mr}$ Watt will not be able to get his way until he sets out to answer them patiently and persuasively. To do that is the prudent course. The imprudent course, on which he seems bent, is to behave as if those who oppose him have no case. For $\mathrm{Mr}$ Watt, the consequence of that will be such a fight with Congress that the Administration will find him a political liability - and will find another Secretary of the Interior. And then there will be no oil and gas from Montana.

\section{Isidore Nabi, RIP}

There has been great confusion in the scientific literature because of a jape that began at the University of Chicago some years ago. A non-existent scientist, Dr Isidore Nabi (whose first name is sometimes spelled Isadore), was blessed with a biography in American Men and Women of Science by a group of scientists including Professor Leigh Van Valen (still at the University of Chicago), Dr Richard C. Lewontin (now a professor at Harvard University) and Dr Richard Lester (now at the Harvard School of Public Health). Although, no doubt, the editors of American Men and Women of Science will be offended to discover that they have been duped, the creation of Nabi from thin air may be thought a harmless joke.

Unfortunately the joke has gone too far. Apparently Nabi's three creators have been in the habit of using his fake existence as a means of concealing their own identity. Earlier this year, for example, a letter supposed to be from Nabi was published in Nature $(290,183 ; 1981)$ making an otherwise plausible point about the controversy over the Natural History Museum. Nabi's name has also turned up elsewhere, even as the author of articles in the journal called Science and Nature. The objection to this use of Nabi's fictional identity as a pseudonym in the scientific literature is twofold. First, it is a deception. Second, it allows people with known opinions on important controversial matters to give a false impression that their opinions are more weighty than truth would allow.

So somehow Nabi has to be banished from the scientific literature. What began as a good joke has become an impediment to sensible discussion. But if Nabi's three creators insist on using his name as a pseudonym, what can simple mortals do? The answer is quite simple - let others than those in the know use Nabi's name frequently, especially when making points conflicting with those who have so far used the pseudonym. It should not be long before they find it necessary to invent another or, better still, to use their own names. 